\title{
Prediction of ground motion in the Osaka sedimentary basin associated with the hypothetical Nankai earthquake
}

\author{
Haruko Sekiguchi • Masayuki Yoshimi • \\ Haruo Horikawa • Kunikazu Yoshida • \\ Sunao Kunimatsu $\cdot$ Kenji Satake
}

Received: 19 June 2007 / Accepted: 19 November 2007 / Published online: 24 January 2008

(C) The Author(s) 2007

\begin{abstract}
We studied the long-period ground motions in the Osaka sedimentary basin, Japan, which contains a 1 - to 3-km thickness of sediments and is the site of many buildings or construction structures with long-natural period. We simulated the broadband ground motions likely to be produced by the hypothetical Nankai earthquake: the earthquake expected to give rise to the most severe long-period ground motion within the basin. For the simulation, we constructed multiscale heterogeneous source models based on the Central Disaster Management Council of Japan (CDMC) source model and adopted a hybrid computation method in which long-period motion and shortperiod motion are computed using a 3-D finite difference method and the stochastic Green's function method, respectively. In computing long-period motions, we used a 3-D structure model of the crust and the Osaka sedimentary basin. The ground motions are estimated to have peak velocities of $50-90 \mathrm{~cm} / \mathrm{s}$, prolonged durations exceeding $300 \mathrm{~s}$, and long predominant periods of $5-10 \mathrm{~s}$ in the area with great thickness of sediments. The predominant periods are in
\end{abstract}

H. Sekiguchi $(\bowtie) \cdot$ M. Yoshimi $\cdot$ H. Horikawa

$\mathrm{K}$. Yoshida $\cdot \mathrm{S}$. Kunimatsu $\cdot$ K. Satake

Geological Survey of Japan,

National Institute of Advanced Industrial

Science and Technology (AIST),

1-1-1 Higashi, Tsukuba-shi,

Ibaraki 305-8567, Japan

e-mail: haruko.sekiguchi@aist.go.jp agreement with an approximate evaluation by $4 \mathrm{H} /$ $V_{\mathrm{s}}$ where $H$ and $V_{\mathrm{s}}$ are the thickness of the sediment and the average $\mathrm{S}$ wave velocity, respectively.

Keywords Long-period ground motion . Ground motion prediction - Osaka Basin .

Nankai earthquake $\cdot$ Hybrid method .

Finite-difference method · Fluctuation .

Subsurface structure

\section{Introduction}

Long-period ground motion associated with largescale $(M>7.5)$ earthquakes is one of the major threats to modern industrialized countries in which longperiod structures such as high-rise buildings, long cable-stayed bridges, and oil storage tanks are abundant. The 2003 Tokachi-oki earthquake (Mw 8.0) led to the sloshing of oil tanks and large fires in some of the tanks located upon the Yufutsu Plain, more than $200 \mathrm{~km}$ from the hypocenter. In this area, long-period ground motion was amplified and prolonged by the great thickness of the underlying sediments (Hatayama et al. 2004). This event clearly demonstrated the threat of long-period ground motions and the fact that many large-scale structures within Japan potentially face the same threat.

We conducted a series of long-period ground motion predictions, including geophysical prospecting (where necessary), subsurface structural modeling, 
source modeling for possible large earthquakes, and numerical simulations of the wavefields arising from such earthquakes. The study areas were chosen with regard to the thickness of sediments, distance from possible source areas of great earthquakes, and the existence of long-period structures because destructive long-period ground motions develop when seismic waves generated by a sufficiently large earthquake propagate into large-scale basins that contain a sufficient thickness of sediments.

In this article, we present the results of a ground motion simulation in the Osaka Basin based on the hypothetical Nankai earthquake.

The Osaka Basin is an elliptically shaped sedimentary basin surrounded by mountains and islands of bedrock. The western half of the basin consists of Osaka Bay, while the eastern half is emergent land. The basin is filled with sediments, around $1-3 \mathrm{~km}$ thick, of the Osaka Group (Late Pliocene to Pleistocene); terrace deposits; and layers of alluvium.

The possible sources of long-period strong ground motions within the basin are located about $200 \mathrm{~km}$ to the south along the Nankai trough where the Philippine Sea Plate is subducting beneath the Japanese Arc. Historical documents from as long ago as the seventh century indicate that great earthquakes have occurred in this area with a recurrence period of 100-200 years (Ando 1975); some events ruptured the entire $700-\mathrm{km}$-long trough, whereas others ruptured only the eastern (Tokai or Tonankai earthquake) or western halves of the trough (Nankai earthquake). The probabilities that the next great earthquakes within the Nankai and Tonankai areas will occur within the next 30 years are very high: $50 \%$ and $60-70 \%$, respectively (Headquarters for Earthquake Research Promotion of Japan [HERP] 2007).

The seismic intensities of future Nankai earthquakes have been evaluated by HERP and the Central Disaster Management Council of Japan (CDMC), and both organizations have developed finite-fault source models from a diverse range of geologic, geophysical, geomorphologic, and seismological data (HERP 2001; CDMC 2003).

We constructed source models for the future Nankai earthquake and conducted numerical simulations of broadband ground motions using a hybrid computation method involving a combination of a 3D finite-difference calculation for low-frequency motions and a stochastic Green's function method for high-frequency motions. Predictions of ground motion in the Osaka Basin associated with the hypothetical Nankai earthquake have also been reported by Tsurugi et al. (2005) and Kamae and Kawabe (2005) who adopted the source models developed by CDMC and HERP, respectively, assuming constant slip on each asperity, constant rupture propagation velocity, and rectangular fault planes. In the present study, we adopted the CDMC model with some modifications, considering multiscale heterogeneity in slip distribution and rupture propagation. Comparisons of our results with those of the above studies are presented later in the text.

\section{Subsurface velocity structure models}

Three velocity structure models at different scales are used in calculating ground motions: a 3-D crustal structure model, a 3-D basin model, and an alluvium/ diluvium model.

\subsection{3-D crustal structure model}

We employ a 3-D crustal velocity structure model based on that of Furumura (2002), consisting of continental crust, a subducting oceanic plate, and an upper mantle. The continental crust is divided into three layers: a shallow part $(<4 \mathrm{~km})$, an upper crust, and a lower crust. The subducting oceanic plate is divided into three layers: oceanic-1, oceanic-3, and lower slab with thicknesses of 2, 7, and $27 \mathrm{~km}$, respectively. The depth to the Moho and to the Philippine Sea Plate are taken from Ryoki (1999) and Yamazaki and Ooida (1985), respectively (Fig. 1). The depth to the Conrad discontinuity-the boundary between the upper and lower crust - is set to $42 \%$ of the Moho depth. Table 1 lists the material properties, $\mathrm{P}$ and $\mathrm{S}$ wave velocities, density, and attenuation factor $Q$ assumed for each layer (Yoshimi et al. 2005; Yoshimi and Sekiguchi 2006). These properties are constant within each layer, except in the oceanic plate in which seismic velocities are depthdependent.

\subsection{3-D Osaka sedimentary basin structure model}

We use a 3-D velocity structure model of the Osaka sedimentary basin, developed by integrating geolog- 

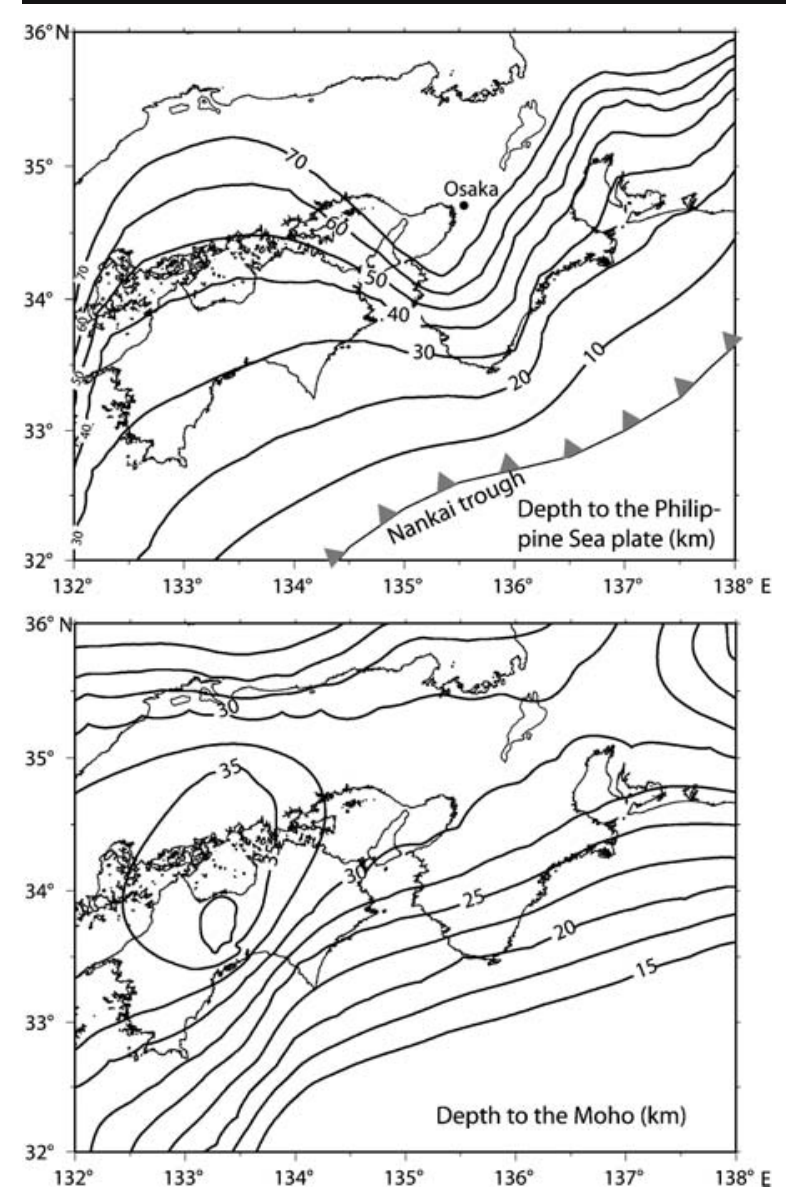

Fig. 1 Depth to the top of the Philippine Sea Plate and depth to the Moho (Furumura 2002) assumed in the 3-D finitedifference computation

Table 1 Velocity structure of the employed crustal model

\begin{tabular}{lllll}
\hline Layer & $V_{\mathrm{p}}(\mathrm{m} / \mathrm{s})$ & $V_{\mathrm{s}}(\mathrm{m} / \mathrm{s})$ & $\begin{array}{l}\text { Density } \\
\left(\mathrm{g} / \mathrm{cm}^{3}\right)\end{array}$ & $Q$ \\
\hline $0-4 \mathrm{~km}$ & 5,400 & 3,100 & 2.5 & 200 \\
$4 \mathrm{~km}-$ Conrad & 6,000 & 3,600 & 2.7 & 300 \\
$\quad(0.42 \times$ Moho $)$ & & & & \\
$\begin{array}{c}\text { Conrad-Moho } \\
\text { Upper mantle }\end{array}$ & 6,600 & 3,700 & 2.8 & 400 \\
$\quad 7,800$ & 4,200 & 3.3 & 500 \\
$\begin{array}{c}\text { Oceanic } 1 \\
(H=2 \mathrm{~km})\end{array}$ & $5,800+18.8 \mathrm{z}$ & $V_{\mathrm{p}} / 1.78$ & 3.1 & 200 \\
$\begin{array}{c}\text { Oceanic 3 } \\
(H=7 \mathrm{~km})\end{array}$ & $6,300+15.5 \mathrm{z}$ & $V_{\mathrm{p}} / 1.78$ & 3.4 & 300 \\
$\begin{array}{c}\text { Lower slab } \\
(H=27 \mathrm{~km})\end{array}$ & $8,100+3.5 \mathrm{z}$ & $V_{\mathrm{p}} / 1.78$ & 3.2 & 1,000 \\
\hline
\end{tabular}

z: depth $(\mathrm{km})$ ical and geophysical data obtained from 47 reflection surveys, 88 deep borehole surveys, and gravity measurements (Horikawa et al. 2003; GSJ/AIST 2004). $P$ wave velocity is modeled from its empirical relations to depth and depositional age. The density and $\mathrm{S}$ wave velocity are deduced from the $\mathrm{P}$ wave velocity on the basis of the theory of poroelasticity (Horikawa et al. 2002). The attenuation factor, $Q$, is assumed to be $Q=0.165 V_{\mathrm{s}} \times \exp (-0.65 f)$ for frequencies lower than $1 \mathrm{~Hz}$ and $Q=0.125 V_{\mathrm{s}} \times f^{0.5}$ for frequencies higher than $1 \mathrm{~Hz}$ where $V_{\mathrm{S}}(\mathrm{m} / \mathrm{s})$ is the $\mathrm{S}$ wave velocity and $f$ is frequency (Horike 2002, personal communication). The sediments within the basin are expressed as a volume with spatially variable seismic velocities and density rather than as a stack of layers with constant material parameters. Depth to the bedrock in the model is shown in Fig. 2, and cross-sections showing the distribution of $\mathrm{S}$ wave velocity across the basin are presented in Fig. 3. The deepest point of the basin floor is in the middle of Osaka Bay where it is more than $2.5 \mathrm{~km}$ below the seafloor. Overhanging structures formed by repeated thrust faulting are realistically expressed in this model, whereas these structures were described as smooth ramps in previous models (Kagawa et al. 1993, 2004; Miyakoshi et al. 1999).

The predominant period, estimated approximately by $4 H / V_{\mathrm{s}}$ (where $H$ is the thickness of the sediments and $V_{\mathrm{s}}$ the average $\mathrm{S}$ wave velocity), is $4-6 \mathrm{~s}$ above the rise in the basin floor-due to reverse faulting along the Uemachi (reverse) fault system-and 6-9 s along the bayside. The validity of the model was examined by simulations of small to moderate earth-

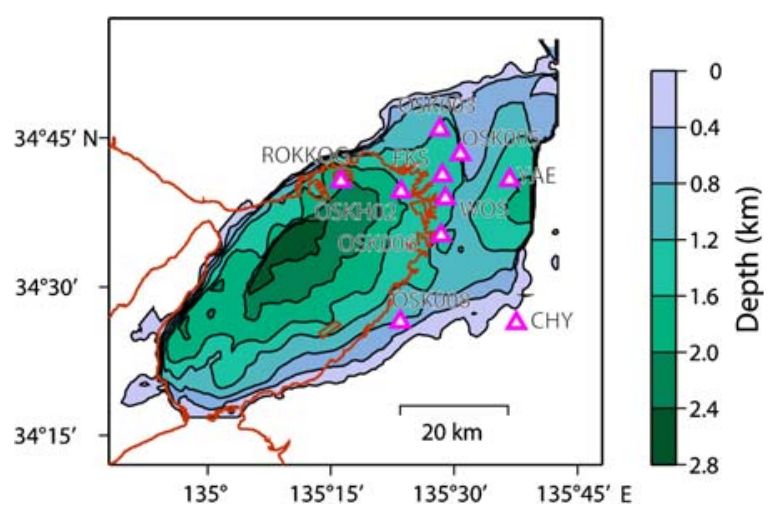

Fig. 2 Depth to bedrock in the model of the Osaka sedimentary basin (Horikawa et al. 2003) and locations of stations selected to show synthesized ground motions 
Fig. 3 a, b, c, d, e, and $\mathbf{f}$ Cross-sections showing the distribution of $\mathrm{S}$ wave velocity predicted in a $3-\mathrm{D}$ model of the Osaka sedimentary basin (Horikawa et al. 2003). The locations of the cross-sections are shown in the index map (lower left)

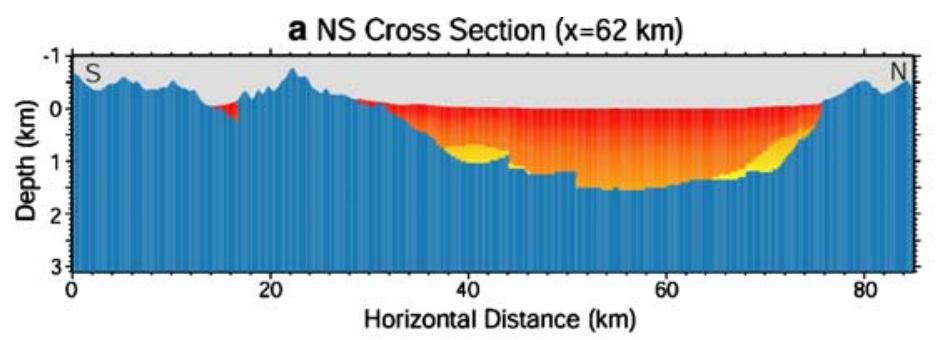

b EW Cross Section $(y=45 \mathrm{~km})$

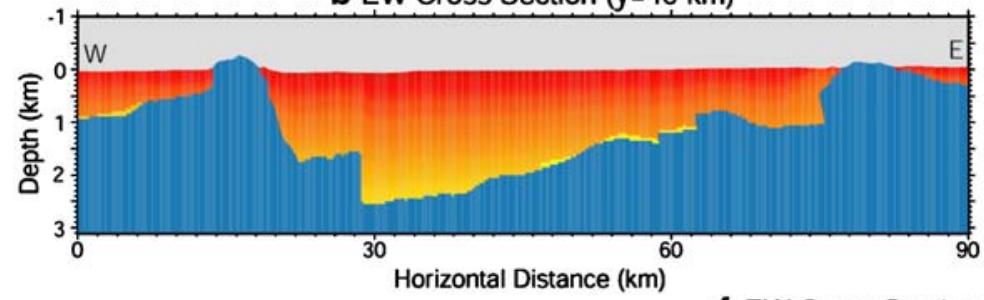

f EW Cross Section

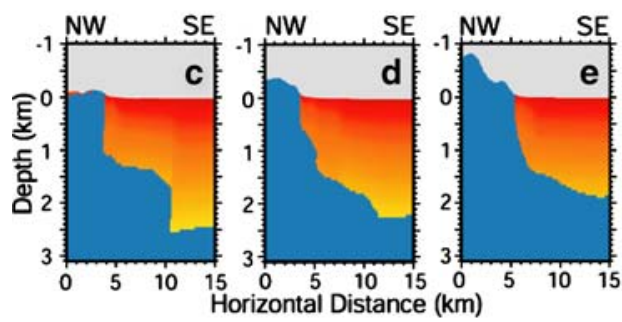
$(y=35 \mathrm{~km})$

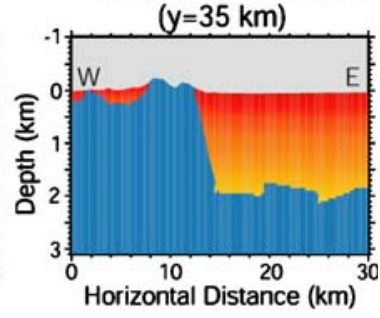

Vs $(\mathrm{m} / \mathrm{s})$
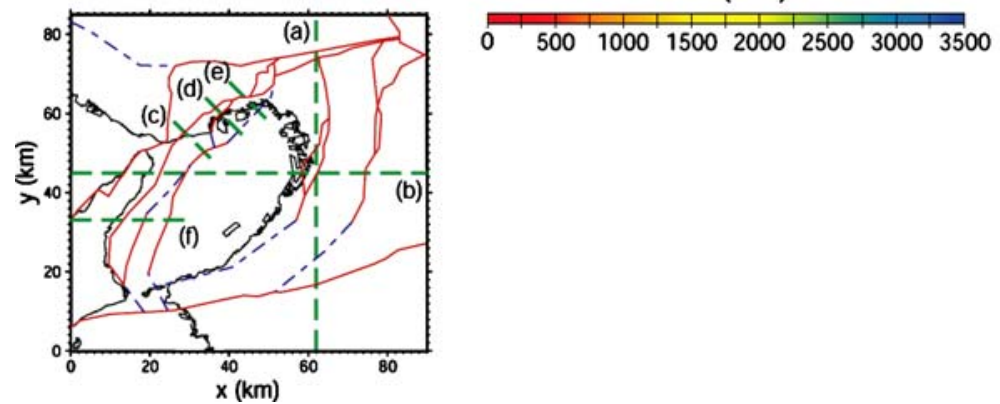

quakes, and the obtained discrepancies were used to tune the model.

\subsection{Alluvium/diluvium model}

We use an alluvium/diluvium velocity structure model for the Osaka sedimentary basin (Yoshida et al. 2006) constructed from more than 30,000 shallow borehole data (Geotechnical Information Database in Kanasai: Kansai Geo-informatics Council). Cross-sections showing the $\mathrm{S}$ wave velocity distribution are displayed in Fig. 4. Nonlinear characteristics of the soil, such as the strain dependency of rigidity and the attenuation factor, are set according to the results of soil tests of sands and clays from within the basin (Koyamada 2005).

\section{Multiscale heterogeneous source model}

We construct a hypothetical Nankai earthquake source model by modifying the CDMC source model. The fault plane of the CDMC model consists of six areas, each with constant slip: five asperities and a background area. The asperities are about 20-100 km wide. The entire fault plane is assumed to rupture with a constant velocity, as follows: the rupture starts from a nucleation point in the background area and 


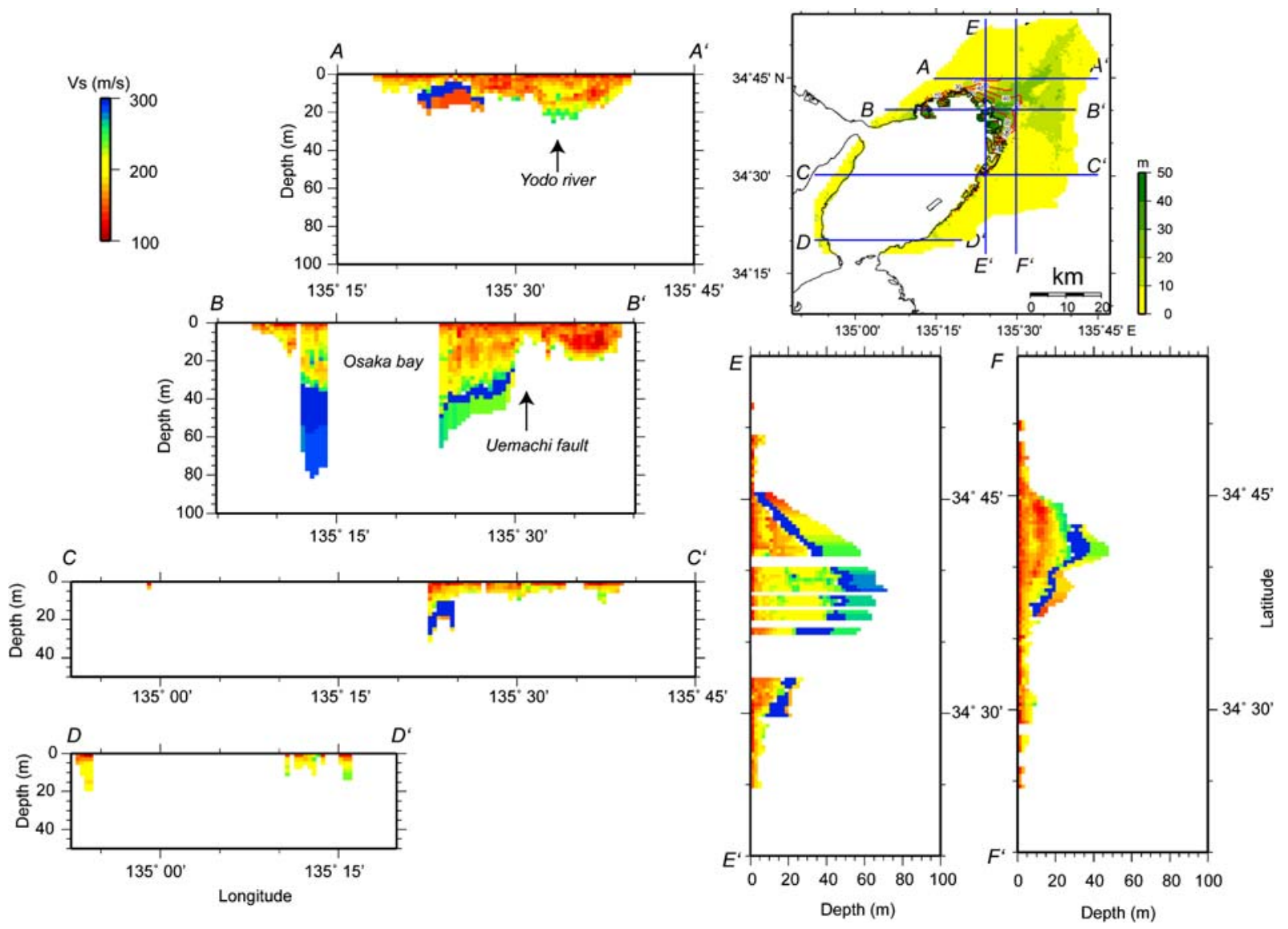

Fig. 4 Cross-sections showing the distribution of S wave velocity predicted in the alluvium/deluvium model (Yoshida et al. 2006)

the rupture in each asperity propagates concentrically from a subnucleation point at the moment the rupture front reaches the point. Because no heterogeneities smaller than these asperities are included in the model, the resultant ground motions lack a frequency component higher than the dominant frequency of the directivity pulses from the asperities (approximately $0.05-0.1 \mathrm{~Hz}$ ). Source processes revealed by waveform inversion studies show spatially and temporally complex features in wavelength smaller than the fault length; therefore, a source model with multiscale heterogeneity, such as fractal-like fluctuation, is preferable to synthesize ground motions more realistically in the broadband frequency range.

Multiscale heterogeneity is introduced to both the slip distribution and the rupture velocity distribution (Fig. 5) using the following process of Sekiguchi and Yoshimi (2006). First, patches with various sizes (smaller than half the size of the smallest asperity and

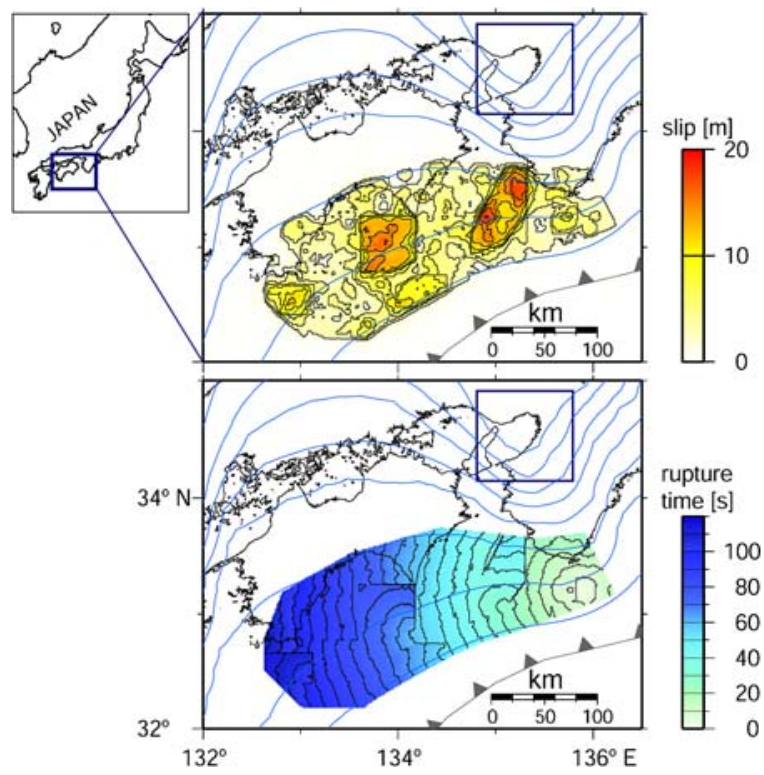

Fig. 5 Multiscale heterogeneous source model for the future Nankai earthquake (top fault slip, bottom rupture time) 
following a fractal distribution) are dispersed over the rupture area at random. The slip and rupture velocity inside each patch are then randomly increased or decreased. The amount of increase/decrease of the slip is proportional to the radius of the patch, starting from a value of half of the average slip over the entire rupture area. Fluctuation of the rupture velocity is set to $250 \mathrm{~m} / \mathrm{s}$, which gives adequate variation relative to that observed in many source inversion results. Finally, the amplitude of the slip spectrum is adjusted to decay at $k^{-1.75}$, where $k$ is wave number, as derived by Mai and Beroza (2002) who conducted a stochastic analysis of earthquake slip complexity using numerous published source models. For the time history of slip on the fault, a slip velocity time function approximated from a dynamic rupture simulation (Nakamura and Miyatake 2000) is assumed. The fault plane is located in the curved upper surface of the Philippine Sea Plate model.

The source spectrum is improved with this modification (Fig. 6): the source spectrum of the original CDMC model decays faster than $\omega^{-2}$ decay, where $\omega$ is angular frequency, resulting in a deficiency in the frequency range higher than $0.1 \mathrm{~Hz}$; in contrast, the source spectra of the multiscale heterogeneous models show $\omega^{-2}$ decay and no clear deficiency. In addition, the spectra of the multiscale heterogeneous models

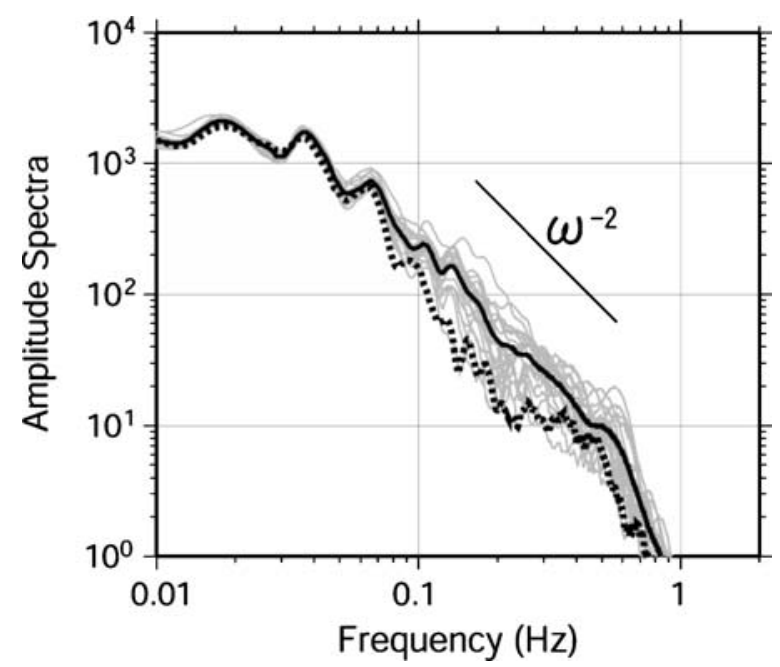

Fig. 6 Source spectra of the CDMC source model (dotted line) and 20 multiscale heterogeneous source models with different distribution pattern of patches (thin gray lines). The source spectrum of the multiscale heterogeneous source model shown in Fig. 5 is drawn with a bold line. $\omega$ is angular frequency converge to that of the CDMC model at lower frequencies, indicating that the macroscopic features of the initial source model are retained.

\section{Ground motion simulation}

We compute broadband ground motions using a hybrid technique (Sekiguchi et al. 2006). Synthetic ground motion on engineering basement $\left(V_{\mathrm{s}}=500 \mathrm{~m} / \mathrm{s}\right)$ is attained by combining a lower-frequency motion (up to $0.37 \mathrm{~Hz}$ ) calculated using a 3-D finite-difference method (Pitarka 1999) and a higher-frequency motion synthesized with the extended stochastic Green's function method (ESGFM) (Onishi and Horike 2000), considering frequency-dependent envelopes in the Osaka Basin (Horikawa et al. 2005). The ground motion at the surface is then calculated from the synthetic ground motion on engineering basement using an equivalent linear method (DYNEQ; Yoshida and Suetomi 1996) and considering the nonlinear response of the alluvium/diluvium layers.

The ESGFM enables generation of three components of $\mathrm{P}$ and $\mathrm{S}$ waves by employing a technique improved from that of Boore (1983) to generate highfrequency waveforms for a small earthquake. Improvements were made in terms of the radiation pattern, geometrical spreading, and attenuation and amplification along the ray path. The characteristic shape of the high-frequency envelope was derived using observed waveforms in the Osaka Basin for earthquakes around the Nankai trough (Horikawa et al. 2005).

In the finite-difference calculation, wave attenuation $(Q)$ is incorporated using the method proposed by Graves (1996) where $Q$ is assumed to be proportional to frequency and there is no difference between $Q_{\mathrm{s}}$ and $Q_{\mathrm{p}}$. The reference frequency is set to $0.2 \mathrm{~Hz}$; this has been validated by comparing the observed attenuation in a low-frequency range with the attenuation of synthetic ground motions obtained using the 3-D crustal structure model.

\section{Results and discussion}

Figures 7 and 8 show the broadband velocity waveforms and velocity response spectra (with a damping factor, $h$, of 0.01 ), respectively, for 10 observation stations located in and around the basin. Station CHY 
case0 N12_6 vel

EW

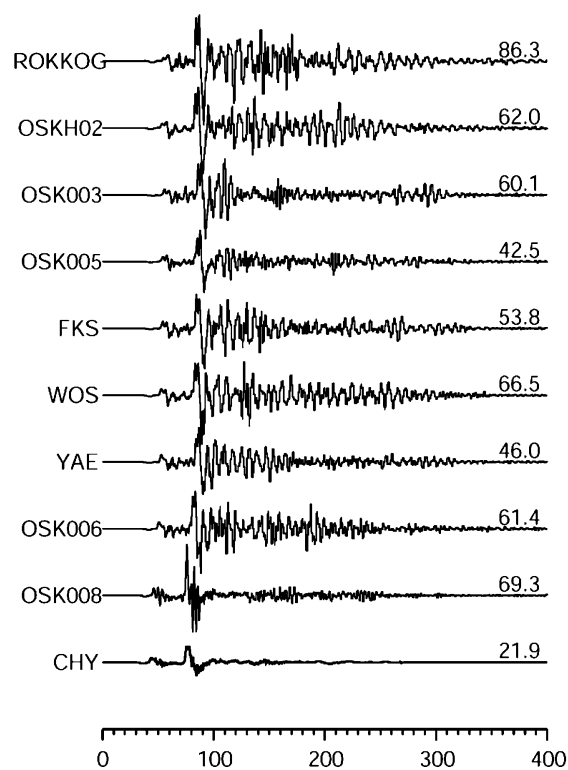

NS
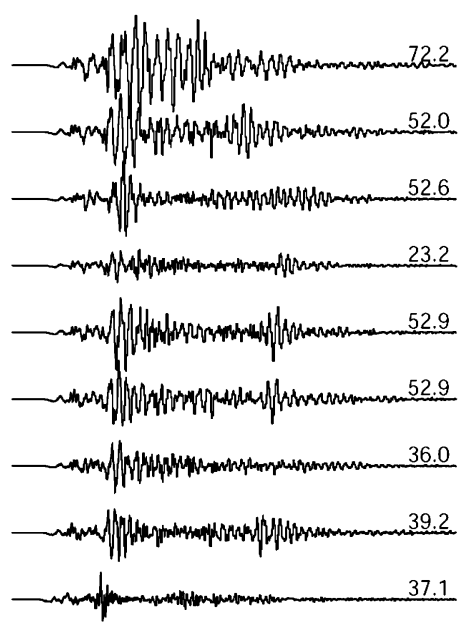

7.8
UD
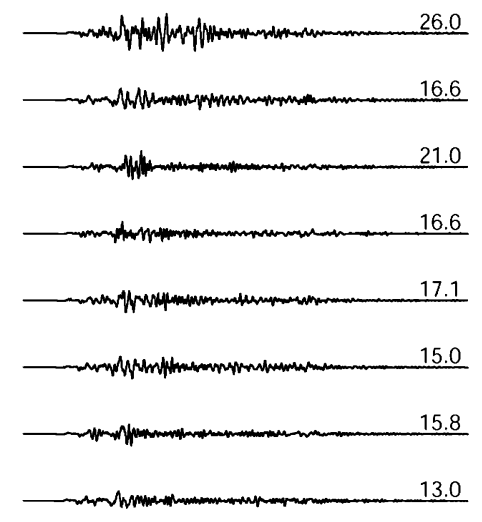

Fig. 7 Broadband velocity waveforms calculated at 10 strong-motion stations in and around the Osaka Basin for the multiscale heterogeneous source model shown in Fig. 5. Locations of stations are shown in Fig. 2

is a bedrock site, whereas the others are situated upon sediment of varying thickness (see Fig. 2). Ground motions at the sediment sites are amplified $(50-90 \mathrm{~cm} / \mathrm{s})$ and prolonged (durations exceed $300 \mathrm{~s}$ ) compared with those recorded at CHY. Long-period components of around 5-10 s dominate the ground motions within the basin, as clearly shown in the velocity response spectra. The peak ground velocity distribution (Fig. 9) reveals that the amplitude is large where the sediments are thick, reflecting the dominance of long-period components within the basin.

Figure 10 (right) shows the velocity response spectra computed at OSKH02 for the 20 multiscale heterogeneous source models with varying distribution patterns of patches. The range in spectral amplitude is relatively large, whereas the source models possess identical macroscopic features (total seismic moment, asperity size, asperity location, asperity seismic moment, and average rupture velocity) and degree of heterogeneity.

Among the synthetic ground motions calculated at the stations, synthetic motion at ROKKOG (where the sediments are thickest among all the stations) yields the largest velocity response at around $10 \mathrm{~s}$. This peak is due to the propagation of surface waves to the ENE within the deepest portion of the basin; the predominant period is in agreement with the approximate estimate obtained using $4 \mathrm{H} / \mathrm{V}_{\mathrm{s}}$.

The reliability of the predicted motions can be assessed from the adequacy of the source modeling, velocity structure modeling, and method used to compute ground motion. In terms of source modeling, model is based on the CDMC source model, which is constructed based on all of the available geological and geophysical data regarding the Nankai source area and historic data of ground shaking. Our source model is modified from the original CDMC model to accommodate the generation of a wide range in periods following the stochastic characteristics of the source spectra. The employed velocity structure model was constructed based on all of the available data and has been verified using a ground motion simulation of small earthquakes. In terms of computation method, the employed hybrid technique incorporates methods that have been validated previously.

Our PGV values are similar to those reported by Tsurugi et al. (2005) (approximately $70 \mathrm{~cm} / \mathrm{s}$ in the Osaka Plain) and Kamae and Kawabe (2005) (approximately $80 \mathrm{~cm} / \mathrm{s}$ in the area of the Osaka Plain 


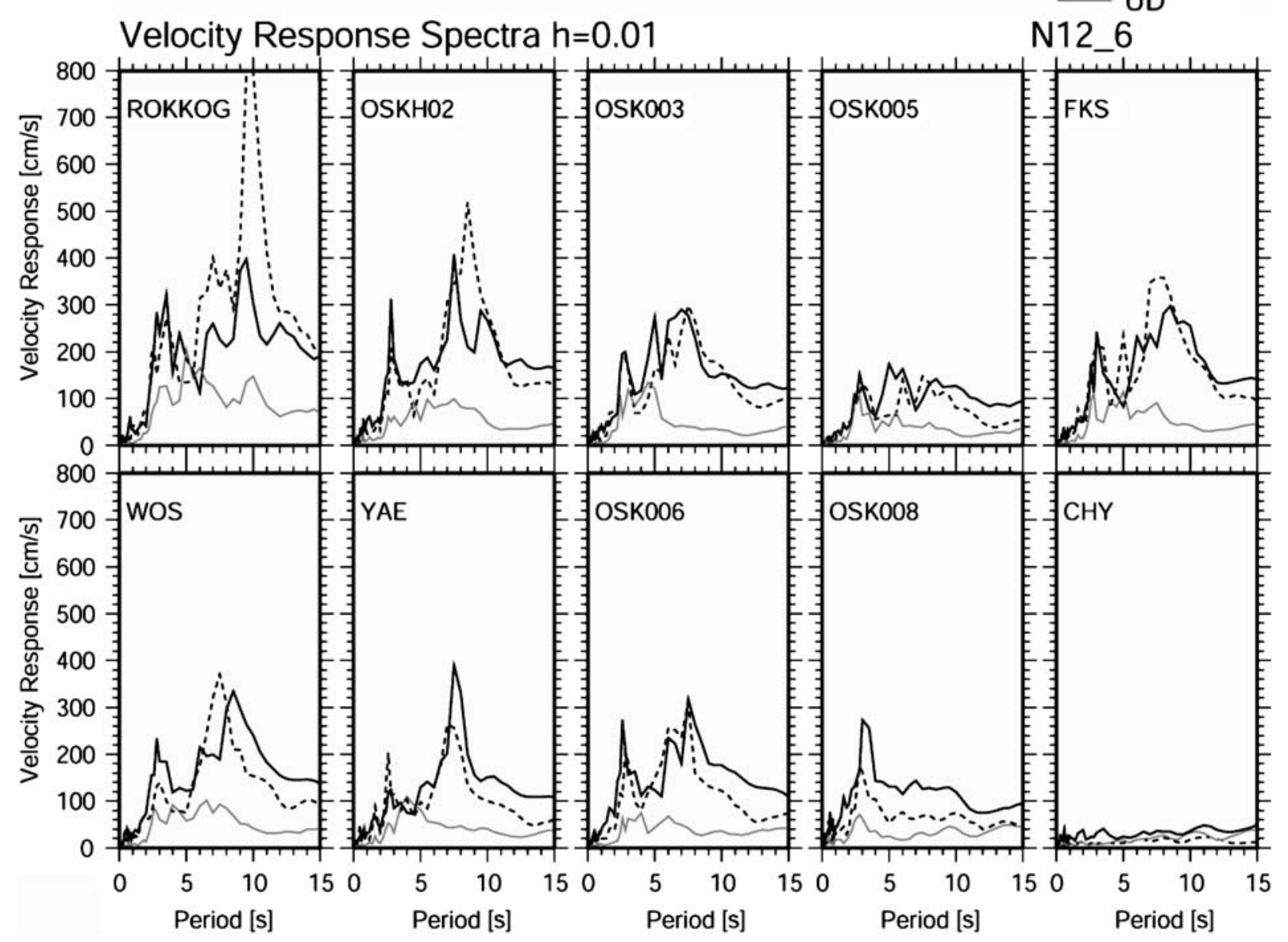

Fig. 8 Velocity response spectra $(h=0.01)$ of the synthetic waveforms shown in Fig. 7

and Kobe City); however, the dominant period of our predicted motions is longer than those reported by Tsurugi et al. (2005) and Kamae and Kawabe (2005), probably because of the differences in the employed source models or expressions of the source models.

\section{Conclusion}

In the present study, we incorporated a realistic source model and adequate subsurface structure model in estimating the long-period ground motions in the Osaka Basin associated with the hypothetical Nankai earthquake. The estimated ground motions in the basin have peak velocities of $50-90 \mathrm{~cm} / \mathrm{s}$, durations of more than $300 \mathrm{~s}$, and predominant periods of 5-10 s, although additional verification is required before being able to provide safety warnings to the public regarding long-period structures.

There exists the need to predict ground motions in those areas of Japan characterized by large-scale basins, plains underlain by great thicknesses of sediment, and long-period structures, as these areas are vulnerable to the effects of long-period ground motions associated with large earthquakes. Although comprehensive studies have considered basins such as the Kanto, Yufutsu, and Nobi, there still remains additional work in terms of the modeling of subsurface structures and earthquake sources. The results of the present study emphasize the importance of not only modeling realistic subsurface structures but also appropriate seismic sources for large earthquakes. 
Fig. 9 Distribution of peak ground velocity predicted by the multiscale heterogeneous source model

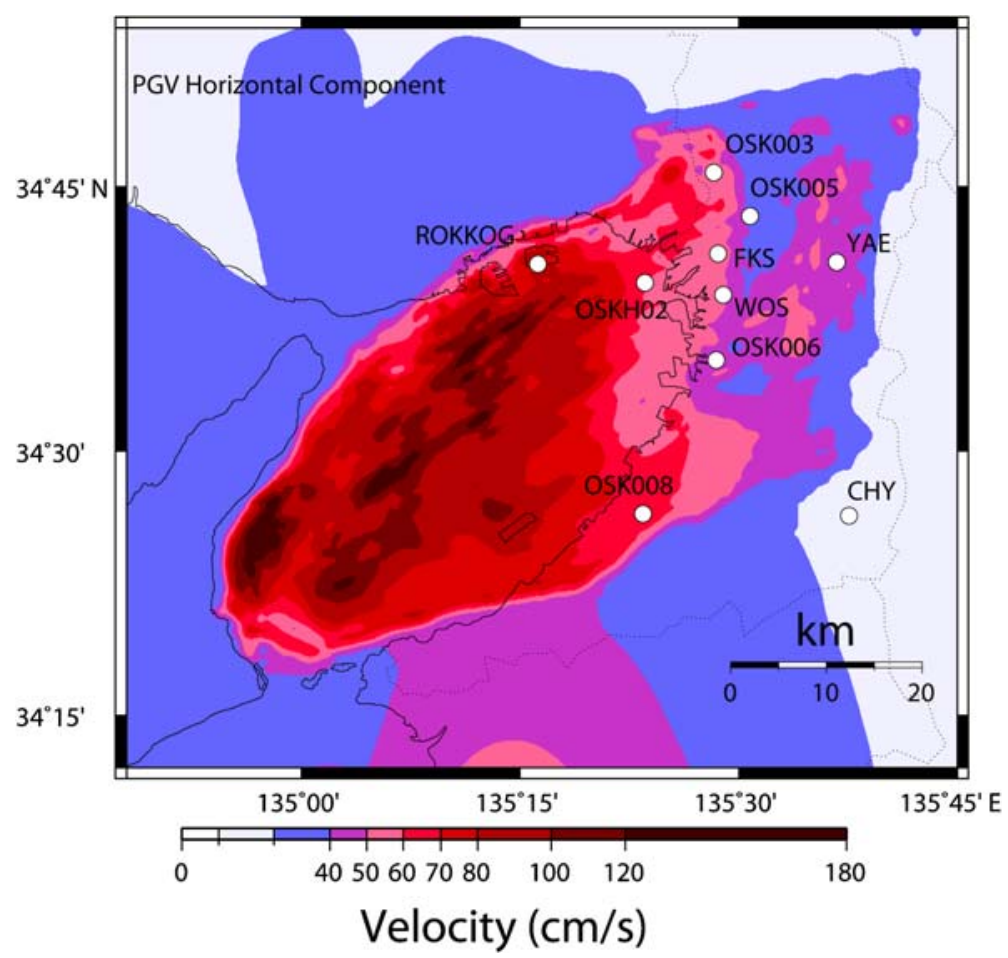

OSKHO2

a a multi-scale heterogeneous source model

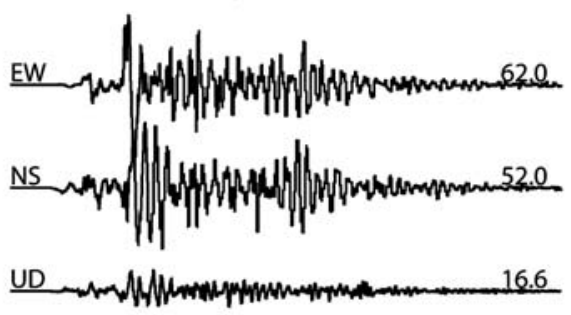

b CDMC source model

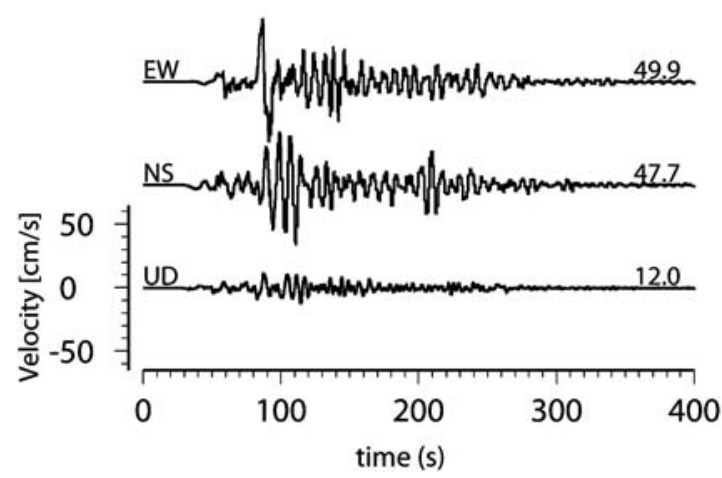

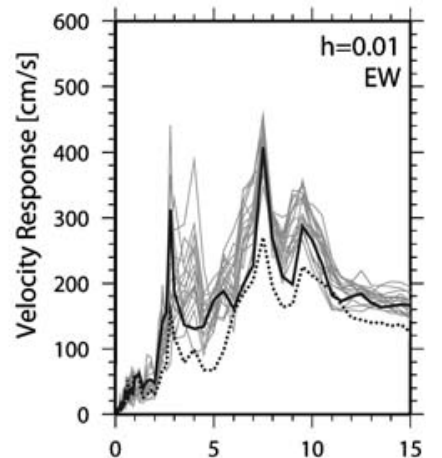

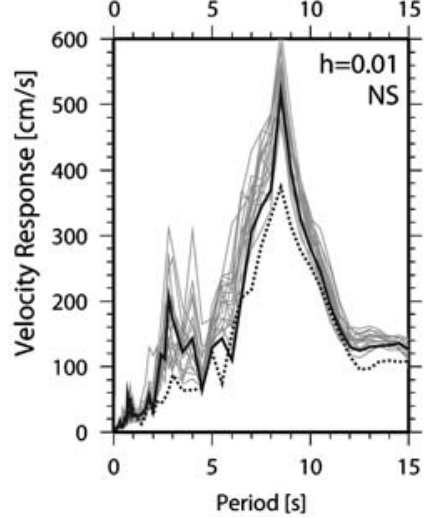


Open Access This article is distributed under the terms of the Creative Commons Attribution Noncommercial License which permits any noncommercial use, distribution, and reproduction in any medium, provided the original author(s) and source are credited.

\section{References}

Ando M (1975) Source mechanisms and tectonic significance of historical earthquakes along the Nankai trough, Japan. Tectonophysics 27:119-140

Boore MD (1983) Stochastic simulation of high-frequency ground motions based on seismological models of the radiated spectra. Bull Seismol Soc Am 73:1865-1894

Central Disaster Management Council of Japan (2003) Conference document, 16th conference of the Special Board of Inquiry on Tonankai and Nankai earthquake. http://www. bousai.go.jp/jishin/chubou/nankai/16/ (in Japanese). Accessed Dec. 16, 2003

Furumura $\mathrm{T}$ (2002) Numerical simulation of seismic wave propagation and strong ground motions in $3 \mathrm{D}$ heterogeneous media. In: Abstracts of the Seismological Society of Japan, 2002 Fall meeting, Pacifico Yokohama, Yokohama, 11-13 Nov 2002:A70

Graves RW (1996) Simulating seismic wave propagation in 3D elastic media using staggered-grid finite differences. Bull Seismol Soc Am 86:1091-1106

GSJ/AIST (2004) A three-dimensional subsurface structure model of the Osaka sedimentary basin, southwest Japan, CD-ROM.

Hatayama K, Zama S, Nishi H, Yamada M, Hirokawa K, Inoue R (2004) Long-period strong ground motion and damage to oil storage tanks due to the 2003 Tokachi-oki earthquake. Zisin 57:83-103 (in Japanese)

Headquarters for Earthquake Research Promotion of Japan (2001) Evaluating strong ground motion regarding earthquakes on Nankai trough (an interim report). http:// sparc1038.jishin.go.jp/main/kyoshindo/01b/index.htm (in Japanese). Accessed Dec. 7, 2001

Headquarters for Earthquake Research Promotion of Japan (2007) Long term evaluation of subduction earthquakes. http://sparc1038.jishin.go.jp/main/choukihyoka/kaikou. htm (in Japanese). Accessed Jan. 1, 2007

Horikawa H, Mizuno K, Satake K, Sekiguchi H, Kase Y, Sugiyama Y, Yokota H, Suehiro M, Pitarka A (2002) Three-dimensional subsurface structure model beneath the Osaka Plain. Annual Report on Active Fault and Paleoearthquake Researches, Geological Survey of Japan 2: 291-324 (in Japanese with English abstract)

Horikawa H, Mizuno K, Ishiyama T, Satake K, Sekiguchi H, Kase Y, Sugiyama Y, Yokota H, Suehiro M, Yokokura T, Iwabuchi Y, Kitada N, Pitarka A (2003) A threedimensional subsurface structure model beneath the Osaka sedimentary basin, southwest Japan, with fault-related structural discontinuities. Annual Report on Active Fault and Paleoearthquake Researches, Geological Survey of Japan 3:225-259 (in Japanese with English abstract)

Horikawa H, Sekiguchi H, Yoshimi M, Yoshida K (2005) Characterization of high-frequency envelopes observed in the Osaka area. Paper presented at the Seismological Society of Japan, 2005 Fall meeting, Hokkaido University, Sapporo, 19-21 Oct 2005(in Japanese)

Horike M (2002) Q value inferred from KiK-net data. In: Abstracts of the Seismological Society of Japan, 2002 Fall meeting, Pacifico Yokohama, Yokohama, 11-13 Nov 2002:B91

Kagawa T, Sawada S, Iwasaki Y, Nanjo J (1993) Modeling the deep sedimentary structure in the Osaka basin. In: Proceedings of the 22nd JSCE Earthquake Engineering Symposium: 199-202 (in Japanese)

Kagawa T, Zhao B, Miyakoshi K, Irikura K (2004) Modeling of 3D basin structures for seismic wave simulations based on available information on the target area: case study of the Osaka basin, Japan. Bull Seismol Soc Am 94:1353-1368

Kamae K, Kawabe H (2005) Strong ground motion prediction in Kinki district for Nankai earthquake. The 33rd Symposium of Earthquake Ground Motion, Tokyo, 18 Nov 2005, pp 35-40 (in Japanese with English abstract)

Koyamada K (2005) Effects of soil nonlinearity on evaluation of site response. In: The Architectural Institute of Japan (ed) The research subcommittees on the earthquake ground motion and on the vibration of foundation systems. Proceedings of the 32nd Symposium of Earthquake Ground Motion, AIJ Hall, Tokyo, 7 Jan 2005, pp 97-104 (in Japanese)

Mai PM, Beroza GC (2002) A spatial random field model to characterize complexity in earthquake slip. J Geophys Res 107, DOI: 10.1029/2001JB000588

Miyakoshi K, Kagawa T, Zhao B, Tokubayashi M, Sawada S (1999) Modeling the deep sedimentary structure in the Osaka basin (3). In: Proceedings of the 25th JSCE Earthquake Engineering Symposium:33-36 (in Japanese)

Nakamura H, Miyatake T (2000) An approximate expression of slip velocity time functions for simulation of near-field strong ground motion. Zisin 53:1-9 (in Japanese)

Onishi Y, Horike M (2000) Application of the method for generating 3-component strong ground motions using the stochastic Green's function to the 1995 Hyogo-ken Nanbu earthquake. J Struct Eng 46B:389-398 (in Japanese with English abstract)

Pitarka A (1999) 3D elastic finite-difference modeling of seismic motion using staggered grids with nonuniform spacing. Bull Seismol Soc Am 89:54-68

Ryoki K (1999) Three-dimensional depth structure of the crust and uppermost mantle beneath southwestern Japan and its regional gravity anomalies. Zishin 52:51-63 (in Japanese with English abstract)

Sekiguchi H, Yoshimi M (2006) Multi-scale heterogeneous source model for wide-band ground motion prediction from giant earthquakes along subduction zones. Chikyu Monthly 55:103-109 (in Japanese)

Sekiguchi H, Yoshimi M, Yoshida K, Horikawa H (2006) Broad-band strong ground motion prediction with multiscale heterogeneous rupture models for huge subductionzone earthquakes along the Nankai trough, Japan. In: Pierre-Yves B, Emmanuel C, Cecile C, Fabrice C, Philippe $\mathrm{G}$ (eds) Third International Symposium on the Effects of Surface Geology on Seismic Motion, Grenoble, 30 Aug-1 Sep 2006, vol 1, Laboratoire Central des Ponts et Chaussees, Nancy, 1043:607-616 
Tsurugi M, Zhao B, Petukhin A, Kagawa T (2005) Strong ground motion prediction in Osaka prefecture during the Nankai and Tonankai Earthquake. J Struct Eng 51A:501512 (in Japanese with English abstract)

Yamazaki F, Ooida T (1985) Configuration of subducted Philippine Sea plate beneath the Chubu district, central Japan. Zishin 38:193-201 (in Japanese with English abstract)

Yoshida N, Suetomi I (1996) DYNEQ: a program for seismic response of layered structure based on equivalent linear methodology. Sato Kogyo Engineering Laboratory Report 61-70 (in Japanese)

Yoshimi M, Sekiguchi H (2006) Strong ground motion prediction with multi-scale heterogeneous source models for huge subduction-zone earthquakes along the Nankai trough, Japan. In: Proceedings of the 1st European Conference on Earthquake Eangineering and Seismology, Geneva, Switzerland, 3-8 Sep 2006: ID 1044

Yoshimi M, Sekiguchi H, Horikawa H, Yoshida K (2005) Strong ground motion prediction for huge subductionzone earthquakes along the Nankai trough. In: Apstracts of the IASPEI General Assembly 2005, Santiago, 2-8 Oct 2005, CR-ROM: 543

Yoshida K, Yamamoto K, Sekiguchi H (2006) Developing of a shallow sedimentary structure model for strong-motion predictions in the Osaka sedimentary basin. Annual Report on Active Fault and Paleoearthquake Researches, Geological Survey of Japan (6):123-141 (in Japanese with English abstract) 